\title{
Physical Investigations of Titanium Dioxide Nanorods Film Prepared by Hydrothermal Technique
}

\author{
${ }^{1}$ Reem A. Saleh, ${ }^{1}$ Odai N. Salman*, ${ }^{2}$ Mohammed O. Dawood \\ ${ }^{1}$ Department of Applied Sciences, University of Technology, Iraq \\ ${ }^{2}$ Physics Department, Almustansiriyah University, Iraq
}

\section{Article information}

\section{Article history:}

Received: May, 06, 2021

Accepted: August, 02, 2021

Available online: September, 18, 2021

\section{Keywords:}

Hydrothermal technique,

Optical properties,

Photoluminescence,

$\mathrm{TiO}_{2}$ nanorods

*Corresponding Author:

Odai N. Salman

100125@uotechnology.edu.iq

\begin{abstract}
In this work, well-oriented and homogeneous titanium dioxide $\left(\mathrm{TiO}_{2}\right)$ nanorods (NRs) was synthesized by hydrothermal method. In this method, vertically aligned arrays of $\mathrm{TiO}_{2}$ were built on the conductive Fluorine-Tin-Oxide (FTO) glass substrate. Nanoparticles (NRs) of $\mathrm{TiO}_{2}$ showed a tetragonal shape with a square top face, according to the image of the field emission scanning electron microscope (FE-SEM). The $\mathrm{TiO}_{2}$ NRs are polycrystalline, having two phases: rutile and anatase, according to X-ray diffraction (XRD) analysis. The optical properties of a $\mathrm{TiO}_{2}$ nanorods arrays were examined, including transmittance, absorption coefficient, and energy bandgap. An optical energy band gap of $3.18 \mathrm{eV}$ was obtained. According to the photoluminescence emission measurement, the energy bandgap was $3.3 \mathrm{eV}$. For further study of the optical properties of the $\mathrm{TiO}_{2}$ Nanorods films, reflectance spectrum was used as a function of wavelength to estimate the value of the energy bandgap and its value was $3.45 \mathrm{eV}$. By comparing the values obtained from the three methods, it is found that they are closely alike, which confirms the formation of the $\mathrm{TiO}_{2}$ nanostructure.
\end{abstract}

DOI: 10.53293/jasn.2021.3513.1024, Department of Applied Science, University of Technology

This is an open access article under the CC BY 4.0 License

\section{Introduction}

Titanium dioxide has been extensively researched over the last few decades for its photovoltaic applications, sensors, photocatalysis, dye-sensitized solar cells, integrated circuits, and environmental devices [1,2]. Chemical inertness, nontoxicity, efficiency, physical stability, a strong refractive index, a direct bandgap, and a high melting point are only a few of $\mathrm{TiO}_{2}$ 's physical and chemical features. [3,4]. $\mathrm{TiO}_{2}$ thin films exist in three crystalline phases: brookite, rutile, and anatase [5]. They take different structures; however, their chemistry is the same [2]. The chemical and physical properties of $\mathrm{TiO}_{2}$ depend on the phase structure [6]. Because of its varied morphologies, such as hollow spheres, nanorods, nanotubes, and nanoparticles, titanium dioxide has been researched for a range of uses. Titanium dioxide nanorods (1D) have a one-dimensional shape that provides quick and direct transfer channels for injected electrons, as well as a longer electron diffusion length. [7]. In comparison to its particulate forms, the structure of the $\mathrm{TiO}_{2}$ nanorod has a larger surface area [8]. Chemical bath deposition (CBD), hydrothermal approach, solvothermal, chemical vapor deposition (CVD), and DC reactive magnetron sputtering are some of the synthetic procedures for generating $\mathrm{TiO}_{2}$ nanorod structures that have been documented $[9,10]$. The high reactivity of reactants, facile regulation of solution or interfacial reactions, creation of metastable and 
distinctive condensed phases, decreased air pollution, and low energy consumption all contributed to the growing interest in hydrothermally synthesized compounds. [11]. Due to oxygen vacancies, titanium dioxide $\mathrm{TiO}_{2}$ is an ntype metal oxide semiconductor. Its conductivity arises in proportion to the amount of oxygen lost. It has a high visible transmission, a high refractive index, and high photocatalytic effectiveness [3]. It has a higher charge distribution constant and a larger energy band gap (rutile energy bandgap $=3.05 \mathrm{eV}$ ). Because of its unique chemical/physical properties, $\left(\mathrm{TiO}_{2}\right)$ is used in photovoltaic and electromechanical devices [12]. $\mathrm{TiO}_{2} \mathrm{NRs}$ have narrow grain boundaries, allowing for quick charge carrier transfer. Previous research indicated that $\mathrm{TiO}_{2} \mathrm{NRs} \mathrm{had}$ superior photocatalytic activity than other nanoparticles due to a large number of active sites. $\mathrm{TiO}_{2}$ film has greater surface activity, making it suitable for antibacterial and self-cleaning applications in the industry [13]. $\mathrm{TiO}_{2}$ nanorod arrays can be used as a photocatalytic coating to improve the antifungal and antibacterial efficiency of Ti substrates [14]. In addition to the previously described applications, when the nanostructured $\mathrm{TiO}_{2}$ substrate is used under AM 1.5 illumination, photovoltaic performance reaches a power conversion efficiency of 0.39 percent and a fill factor of 0.47 [15].

In this work, We'll use a hydrothermal approach to make $\mathrm{TiO}_{2} \mathrm{NRs}$ array films on FTO substrates and investigate their optical characteristics. By adjusting the growth parameters, reaction time, temperature, precursor concentration, and substrate orientation. The diameter, length, and density of the nanorods could be altered. The nucleation and development of $\mathrm{TiO}_{2}$ nanorods on FTO are aided by the epitaxial interaction between the FTO substrate and $\mathrm{TiO}_{2}$ with a modest lattice mismatch [16].

\section{Theoretical Part}

\subsection{Hydrothermal Technique}

A hydrothermal operation is any heterogeneous reaction that takes place in the presence of aqueous solvents under high pressure and temperature to dissolve and recrystallize materials that are generally intractable under normal conditions. [17]. The technique is referred to as hydrothermal when water is used as the solvent [18]. Because of its low cost, quick reaction velocity, and simplicity, hydrothermal synthesis has been considered as a popular method for producing titanium dioxide NRs [19]. Also, as shown in Figure 1, Hydrothermal methods could be used to directly prepare well-crystallized and pure nanostructured materials processes, leading to more chemical treatments being avoided [20].

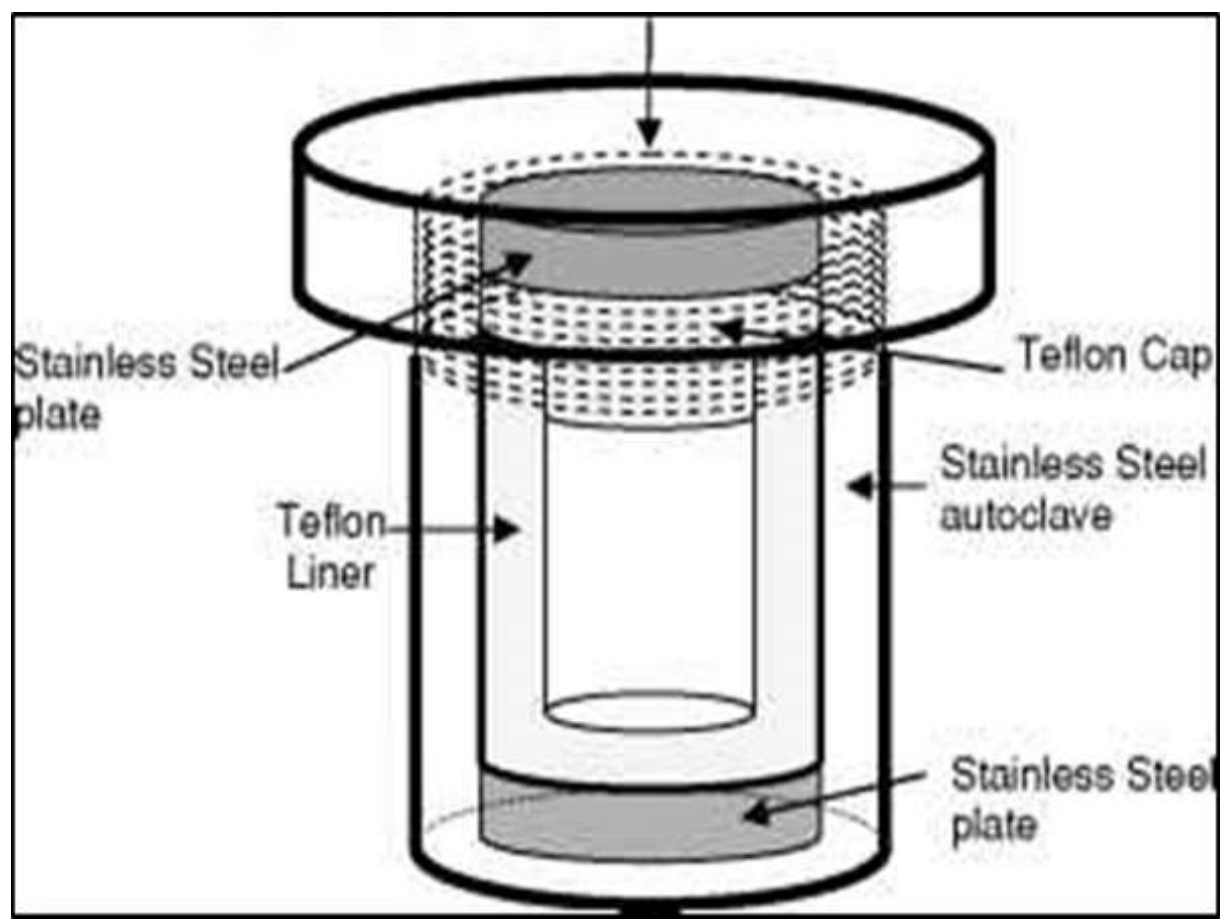

Figure 1: Hydrothermal autoclave parts use to prepare $\mathrm{TiO}_{2}$ nanorods at $180{ }^{\circ} \mathrm{C}$ for $3 \mathrm{~h}$. 


\subsection{Growth Mechanism}

In general, a hydrothermal approach for the synthesis of $\mathrm{TiO}_{2} \mathrm{NRs}$ is carried out in hydrochloric acid (HCl) diluted with deionized water (DI), with Ti (IV) butoxide (TBO) having the structural formula $\mathrm{Ti}\left(\mathrm{OCH}_{2} \mathrm{CH}_{2} \mathrm{CH}_{2} \mathrm{CH}_{3}\right)_{4}$ (or [Ti(RO) 4$]$ ) as a reactant. Several ways to describing $\mathrm{TiO}_{2}$ growth mechanisms have been proposed, all of which are intriguing and useful in our study. When the four-fold Ti precursor ([Ti(RO) $\left.)_{4}\right]$ combines with water, it becomes $\left[\mathrm{Ti}(\mathrm{RO})_{4}\right][21]$.

$$
\begin{aligned}
& \text { Hydrolysis: } \quad \mathrm{Ti}(\mathrm{OR})_{4}+4 \mathrm{H}_{2} \mathrm{O} \rightarrow \mathrm{Ti}(\mathrm{OH})_{4}+4 \mathrm{ROH} \ldots \ldots \ldots \ldots \ldots \ldots \ldots(1) \\
& \text { Dehydration: } \mathrm{Ti}(\mathrm{OH})_{4}+\mathrm{Ti}(\mathrm{OH})_{4} \rightarrow \mathrm{2TiO}_{2}+4 \mathrm{H}_{2} \mathrm{O} \ldots \ldots \ldots \ldots \ldots \ldots \ldots(2) \\
& \mathrm{Ti}(\mathrm{OH})_{4}+\mathrm{Ti}(\mathrm{OR})_{4} \rightarrow 2 \mathrm{TiO}_{2}+4 \mathrm{ROH}
\end{aligned}
$$

The entire reaction via the hydrothermal process between TBO precursor and water is [21]

$$
\mathrm{Ti}(\mathrm{OR})_{4}+2 \mathrm{H}_{2} \mathrm{O} \rightarrow \mathrm{TiO}_{2}+4 \mathrm{ROH}
$$

\section{Experimental Procedure}

The first stage in the experimental part is cleaning the substrates. we use ethanol alcohol with purity of $99.9 \%$ to clean the substrate with ultrasound for 15 minutes. After that, we use deionized water to clean the sample in the second stage for 15 minutes in the same device and then let it dry well before use. The hydrothermal technique in a chemical solution was used to make titanium dioxide nanorods arrays in a Teflon-lined (100 ml) autoclave.

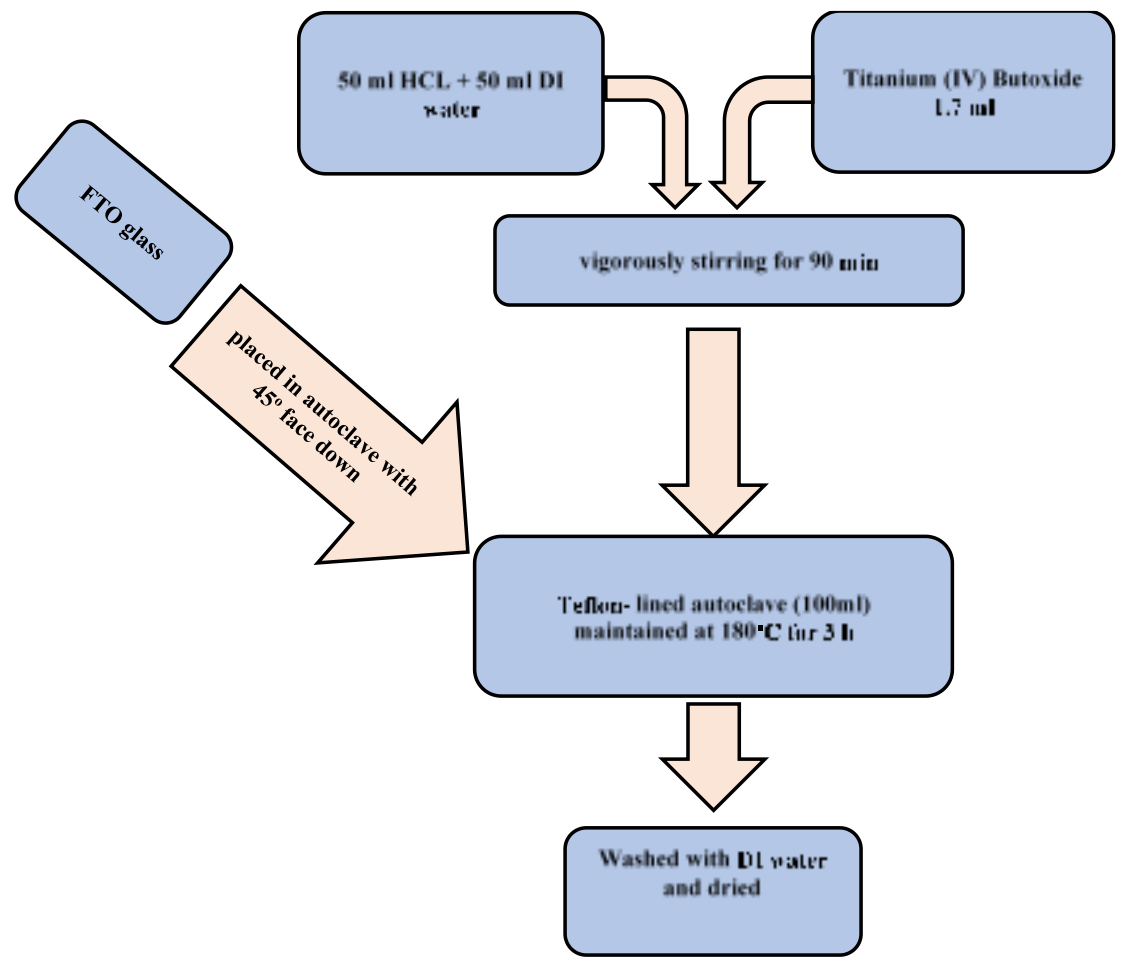

Figure 2: Illustrate the flowchart of experimental work.

Figure 2 shows the flow chart of experimental work. The concentrated hydrochloric acid (35-38 wt. percent) from the Central Drug House (P) Ltd Group in New Delhi was diluted in $50 \mathrm{ml}$ of deionized water (DI). Then, for 90 minutes, aggressively swirl $1.7 \mathrm{ml}$ titanium butoxide $\left(\mathrm{C}_{16} \mathrm{H}_{36} \mathrm{O}_{4} \mathrm{Ti}\right)$ (TBOT) purity $99.9 \%$ (Germany). The solution was then placed into a Teflon-lined autoclave to begin the hydrothermal process. At $180{ }^{\circ} \mathrm{C}$, the hydrothermal reaction takes 3 hours to complete. The autoclave was then taken out of the oven and left to cool to room temperature. After that, DI water was used to rinse the created film. 


\section{Results and Discussion}

\subsection{X-ray Diffraction}

Figure 3 shows the X-ray diffraction of a $\mathrm{TiO}_{2}$ sample prepared on a substrate of FTO using the hydrothermal method. The figure shows the appearance of two phases of rutile and Anatase $\mathrm{TiO}_{2}$ (110) (27.4460), (101) $\left(36.0850^{\circ}\right)$, (211) (54.3216), (221) $\left(65.7480^{\circ}\right)$ for rutile phase respectively, anatase peak (004) (37.9658). After comparing these peaks with the standard of $\mathrm{TiO}_{2}$, for Rutile ICDD card (021-1276) and anatase ICDD card no. (046-1088), we have noticed that the peaks are identical. The benefit of a biphasic $\mathrm{TiO}_{2}$ structure is that the different positions of the valence/conduction bands energy levels of anatase and rutile lead to charge carrier separation [22]. When these two phases are present at the same time, they have a higher Photoelectrochemical activity than when they are present separately. Meanwhile, the biphasic $\mathrm{TiO}_{2}$ structure allows for the use of both phases' properties. For example, rutile has higher chemical stability, refractive index, and bandgap energy than anatase [23], but anatase has a larger specific surface area. The measurement of crystallites size was estimated using the Scherrer equation.

$$
D=\frac{k \lambda}{\beta \cos \theta}
$$

where $\mathrm{D}$ is a crystallite size, $\mathrm{K}$ is the shape factor (0.9), $\beta$ is the Full-width at half maxima (FWHM) (in radians), $\lambda$ is the X-ray wavelength $(0.15418 \mathrm{~nm})$ and $\theta$ is the Brag angle of diffraction. The calculated crystallite size by equation 5 was about $30 \mathrm{~nm}$.

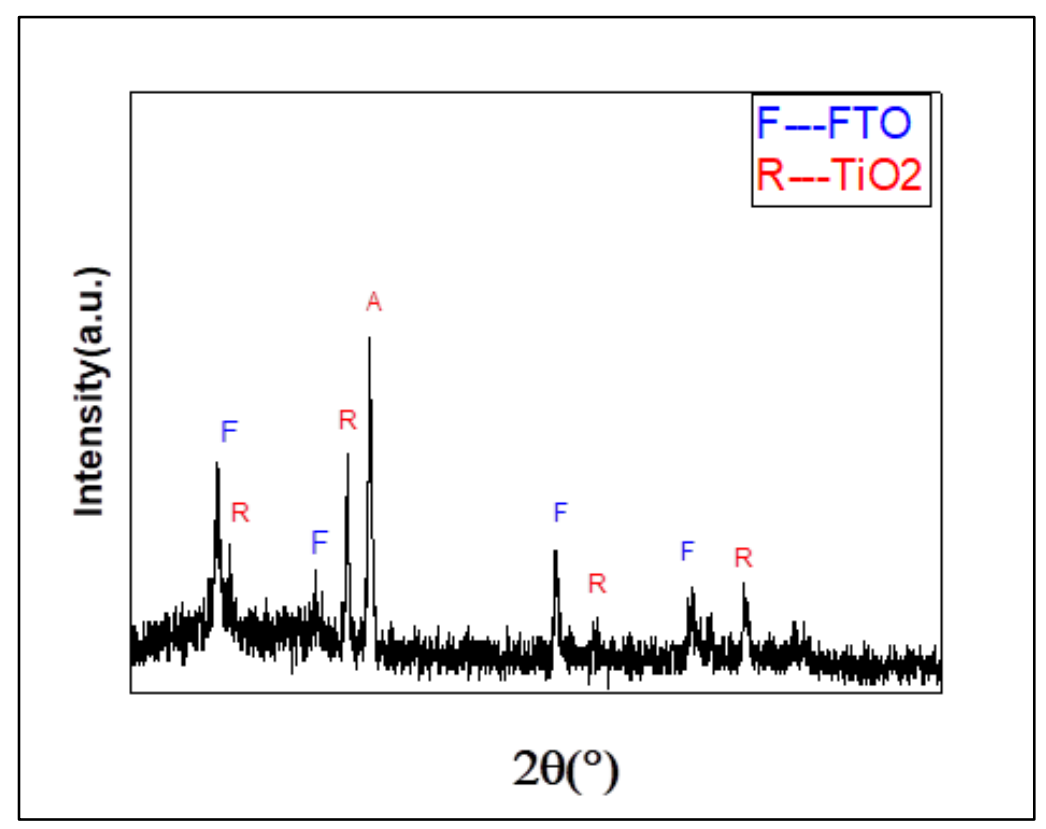

Figure 3. XRD pattern of $\mathrm{TiO}_{2} \mathrm{NRs}$ film prepared on $\mathrm{FTO}$ by hydrothermal method at $180{ }^{\circ} \mathrm{C}$ for $3 \mathrm{~h}$.

\subsection{Field Emission Scanning Electron Microscopy (FE-SEM)}

Figure 4 exhibits the FE-SEM images of the surface morphology of $\mathrm{TiO}_{2}$ NRs arrays synthesized by the hydrothermal method. The images show that the entire surface of the FTO substrate is covered uniformly with ordered $\mathrm{TiO}_{2}$ nanorods, with an average diameter of $65.24 \mathrm{~nm}$ calculated by the software (Image $\mathrm{J}$ ). The nanorods appeared as nanowire bundles. 

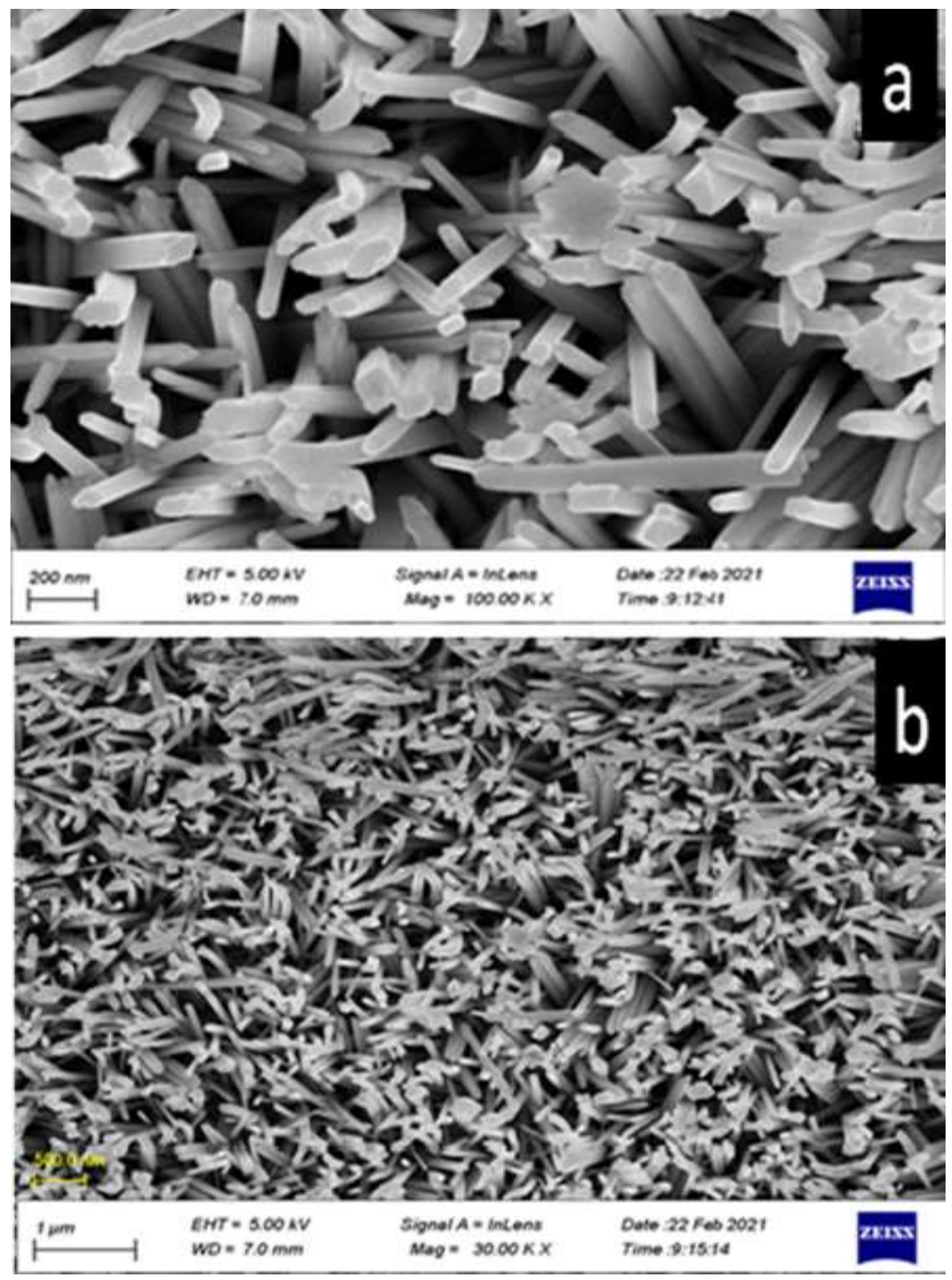

Figure 4: FE-SEM image for the surface of $\mathrm{TiO}_{2} \mathrm{NRs}$ with two magnifications (a) $100 \mathrm{KX}$ (b) $30 \mathrm{KX}$ prepared by hydrothermal method $180^{\circ} \mathrm{C}$ for $3 \mathrm{~h}$.

\subsection{Optical Properties}

\subsubsection{UV-Vis Measurement}

The UV-Visible transmission spectrum and absorption coefficient of the $\mathrm{TiO}_{2} \mathrm{NRs}$ array grown on FTO substrate by hydrothermal technique in the range $(380-1100) \mathrm{nm}$ are shown in Figure $5 \mathrm{a}, \mathrm{b}$, and c. The absorption coefficient spectrum of $\mathrm{TiO}_{2}$ peaks at $380 \mathrm{~nm}$ and then gradually decreases with increasing wavelength, whereas the transmission spectrum increases with increasing wavelength. The optical energy band gap measurement of $3.18 \mathrm{eV}$ confirms the identity of the material [24]. The following equation was used to calculate the energy bandgap [25].

$\alpha h v=A\left(h v-E_{g}\right)^{1 / 2}$

where A is constant and measures the disorder of the material, $\alpha$ absorption coefficient, (hv) (where $h$ is Plank's constant $v$ is the photon frequency), (Eg) bandgap. 


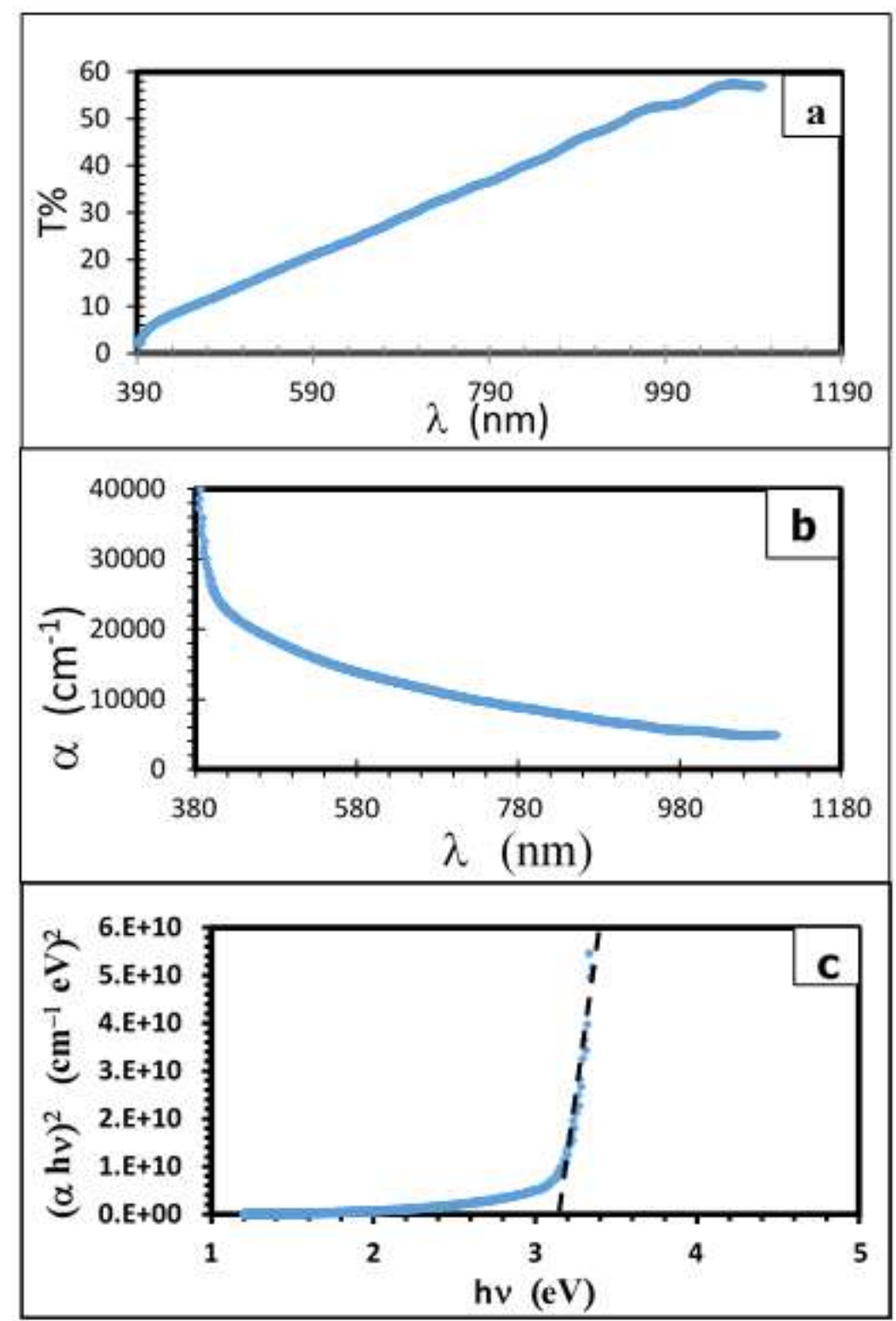

Figure 5: (a) Transmission curves for pure $\mathrm{TiO}_{2} \mathrm{NRs}$ (b) absorption coefficient variation with $\lambda$ for $\mathrm{TiO}_{2} \mathrm{NRs}(\mathrm{C})$. energy gab for $\mathrm{TiO}_{2}$ NRs.

\subsection{Photoluminescence Emission Spectra Properties (PL)}

The interband recombination peak formed at roughly $360 \mathrm{~nm}$ when the $\mathrm{TiO}_{2}$ nanorods film was activated with exciting wavelengths less than $320 \mathrm{~nm}$ [26 ], Due to oxygen vacancies and hydroxyl groups, another peak emerged in the visible region of the spectrum. The most prevalent places for trapped electrons and holes are oxygen vacancies and surface hydroxyl groups. These trapped carriers, which are captured by oxygen vacancies and surface hydroxyl groups, create visible luminescence in samples. [27 ]. The interband recombination peak formed at roughly $360 \mathrm{~nm}$ when the $\mathrm{TiO}_{2}$ nanorods film was activated with exciting wavelengths less than $320 \mathrm{~nm}$ [26 ], and another peak appeared in the visible portion of the spectrum due to oxygen vacancies and hydroxyl groups. For trapped electrons and holes, oxygen vacancies and surface hydroxyl groups are the most common locations. The visible luminescence in samples is caused by these trapped carriers, which are caught by oxygen vacancies and surface hydroxyl groups [28]. 


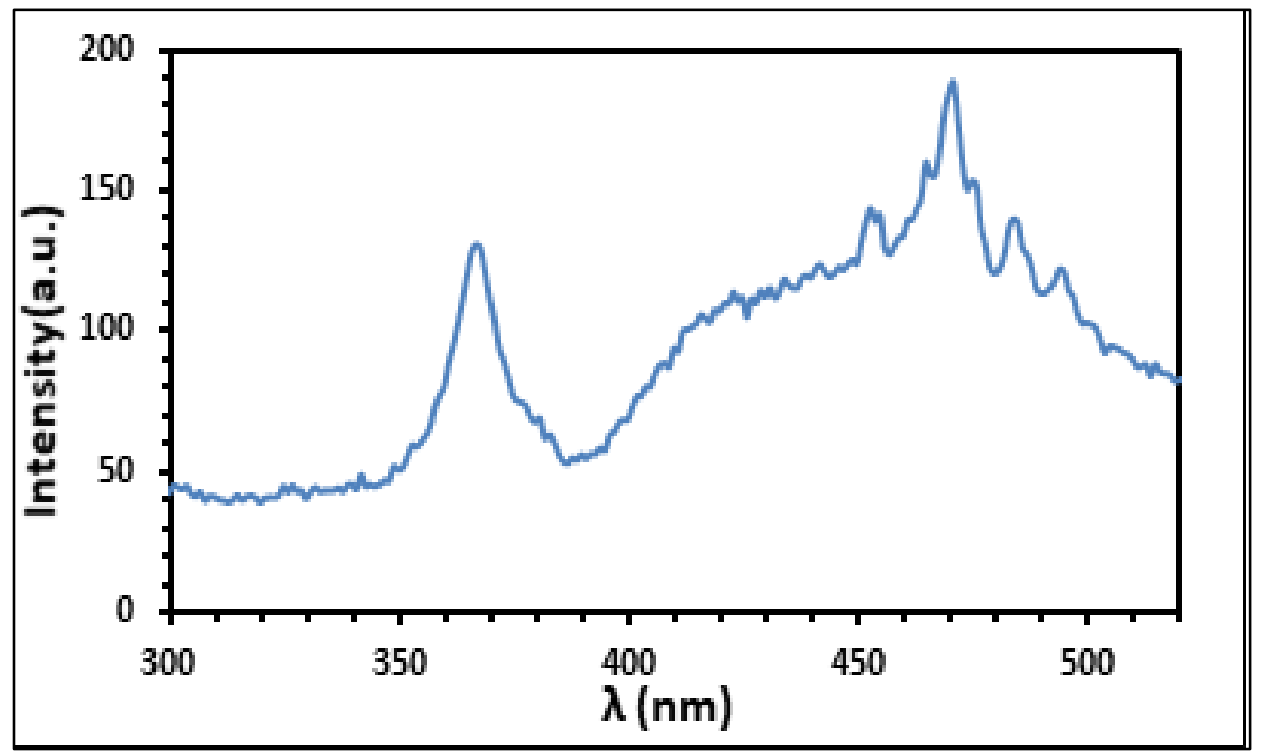

Figure 6: Photoluminescence (PL) for $\mathrm{TiO}_{2}$ NRs on FTO substrate by the hydrothermal method at $180^{\circ} \mathrm{C}$ for $3 \mathrm{~h}$.

\subsection{Reflectance}

For analyzing semiconducting materials, spectroscopic techniques are quite useful. In this study, we used a different method to determine the energy bandgap. As can be observed in Figure 7, the $\mathrm{TiO}_{2}$ reflection begins to rise around 350 and peaks at 390. The energy bandgap can be used to confirm the identity of the material [29]. As in the absorption spectrum, we plot a graph between hv (abscissa) and the square of $\ln \left(\frac{R_{\max }-R \min }{R-R \min }\right)$ to get a straight line. The extrapolation of a straight line to $\left[\boldsymbol{l n}\left(\frac{R_{\max }-\boldsymbol{R} \min }{R-R_{\min }}\right)\right]^{2}=\mathbf{0}$ axis gives the value of the optical energy band gap, as in the following equation: [29].

$$
\ln \left(\frac{R_{\max }-R \min }{R-R \min }\right)=A\left(h v-E_{g}\right)^{1 / 2}
$$

where: $R$ is the reflectance and is given by the ratio of the intensity of reflected beam (I) to incident intensity $\left(I_{0}\right)$. 


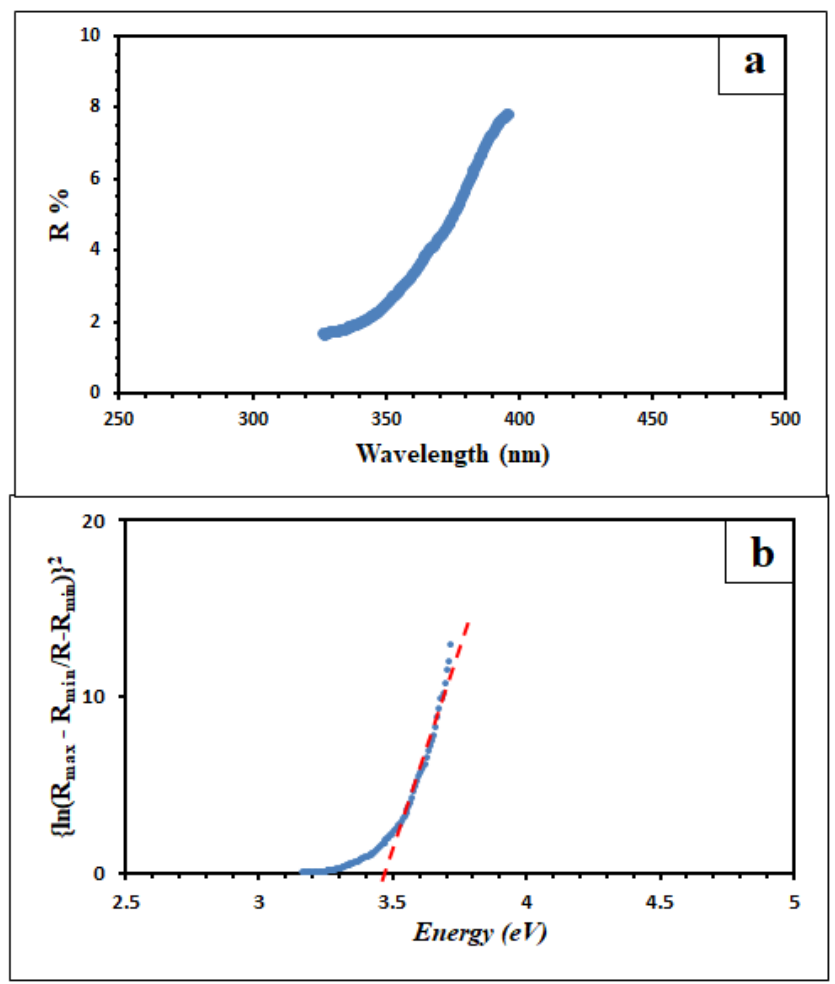

Figure 7: (a) Reflection spectra of $\mathrm{TiO}_{2}$ nanorods by hydrothermal method and (b) energy bandgap.

It is obvious from equation 7 that $\ln [(\mathrm{Rmax}-\mathrm{Rmin}) /(\mathrm{R}-\mathrm{Rmin})]$ and, where $\mathrm{Rmax}$ and $\mathrm{Rmin}$ are the greatest and minimum reflectance in reflection spectra, respectively, and $R$ is the reflectance for any intermediate energy photons measured.

\section{Conclusions}

Physical investigations of titanium dioxide nanorods film have been fabricated via hydrothermal method using TBOT as a precursor. XRD results show a two-phase structure i.e., rutile and anatase. The whole surface of the FTO substrate is uniformly coated with $\mathrm{TiO}_{2}$ nanorods, according to FE-SEM pictures. According to the optical measurement results, there is a high agreement in the values of the optical energy band gap calculated by the three measurements i.e., UV-Vis transmittance, photoluminescence, and reflectance, and its values were 3.18, 3.3, and $3.45 \mathrm{eV}$, respectively.

\section{Conflict of Interest}

There are no conflicts of interest.

\section{References}

[1] Y. Ma, X. Wang, Y. Jia, X. Chen, H. Han, and C. Li, "Titanium dioxide-based nanomaterials for photocatalytic fuel generations," Chem. Rev., vol. 114, pp. 9987-10043, 2014.

[2] K. Nakata and A. Fujishima, "TiO 2 photocatalysis: Design and applications," J. Photochem. Photobiol. C Photochem. Rev., vol. 13, pp. 169-189, 2012.

[3] C. Di Valentin, G. Pacchioni, and A. Selloni, "Reduced and n-type doped $\mathrm{TiO}_{2}$ : nature of $\mathrm{Ti}^{3+}$ species," J. Phys. Chem. C, vol. 113, pp. 20543-20552, 2009.

[4] A. Fujishima and K. Honda, "Electrochemical photolysis of water at a semiconductor electrode," Nature, vol. 238, pp. 37-38, 1972.

[5] T. Bak, J. Nowotny, M. Rekas, and C. C. Sorrell, "Photo-electrochemical hydrogen generation from water using solar energy. materials-related aspects," Int. J. Hydrogen Energy, vol. 27, pp. 991-1022, 2002.

[6] Y.-J. Lin, Y.-H. Chang, W.-D. Yang, and B.-S. Tsai, "Synthesis and characterization of ilmenite $\mathrm{NiTiO}_{3}$ and $\mathrm{CoTiO}_{3}$ prepared by a modified Pechini method," J. Non. Cryst. Solids, vol. 352, pp. 789-794, 2006. 
[7] X. Wang, Z. Li, J. Shi, and Y. Yu, "One-dimensional titanium dioxide nanomaterials: nanowires, nanorods, and nanobelts," Chem. Rev., vol. 114, pp. 9346-9384, 2014.

[8] J.-H. Yoon, S.-R. Jang, R. Vittal, J. Lee, and K.-J. Kim, " $\mathrm{TiO}_{2}$ nanorods as an additive to $\mathrm{TiO}_{2}$ film for improvement in the performance of dye-sensitized solar cells," J. Photochem. Photobiol. A Chem., vol. 180, pp. 184-188, 2006.

[9] L. Meng, H. Chen, C. Li, and M. P. Dos Santos, "Growth of the [110] oriented $\mathrm{TiO}_{2}$ nanorods on ITO substrates by sputtering technique for dye-sensitized solar cells," Front. Mater., vol. 1, p. 14, 2014.

[10] M. Lv et al., "Densely aligned rutile $\mathrm{TiO}_{2}$ nanorod arrays with high surface area for efficient dye-sensitized solar cells," Nanoscale, vol. 4, pp. 5872-5879, 2012.

[11] K. Pugazhendhi et al., "Hybrid $\mathrm{TiO}_{2} / \mathrm{ZnO}$ and $\mathrm{TiO}_{2} / \mathrm{Al}$ plasmon impregnated $\mathrm{ZnO}$ nanocomposite photoanodes for DSSCs: synthesis and characterization," Mater. Res. Express, vol. 5, p. 45053, 2018.

[12] X. Liu et al., "Enhanced photocatalytic activity of CdS-decorated $\mathrm{TiO}_{2} /$ carbon core-shell microspheres derived from microcrystalline cellulose," Materials (Basel), vol. 9, p. 245, 2016.

[13] L. Chen et al., "Preparation of $\mathrm{TiO}_{2}$ nanofilm via sol-gel process and its photocatalytic activity for degradation of methyl orange," Ceram. Int., vol. 35, pp. 3275-3280, 2009.

[14] B. Liu and E. S. Aydil, "Growth of oriented single-crystalline rutile $\mathrm{TiO}_{2}$ nanorods on transparent conducting substrates for dye-sensitized solar cells," J. Am. Chem. Soc., vol. 131, pp. 3985-3990, 2009.

[15] Q. Wei, K. Hirota, K. Tajima, and K. Hashimoto, "Design and synthesis of $\mathrm{TiO}_{2}$ nanorod assemblies and their application for photovoltaic devices," Chem. Mater., vol. 18, pp. 5080-5087, 2006.

[16] L. Jia, J. Qiu, L. Du, Z. Li, H. Liu, and S. Ge, " $\mathrm{TiO}_{2}$ nanorod arrays as a photocatalytic coating enhanced antifungal and antibacterial efficiency of Ti substrates," Nanomedicine, vol. 12, pp. 761-776, 2017.

[17] K. Byrappa and T. Adschiri, "Hydrothermal technology for nanotechnology," Prog. Cryst. growth Charact. Mater., vol. 53, pp. 117-166, 2007.

[18] T. A. Kandel, R. Dillert, A. Feldhoff, and D. W. Bahnemann, "Direct synthesis of photocatalytically active rutile $\mathrm{TiO}_{2}$ nanorods partly decorated with anatase nanoparticles," J. Phys. Chem. C, vol. 114, pp. 49094915, 2010.

[19] M. Iraj, F. D. Nayeri, E. Asl-Soleimani, and K. Narimani, "Controlled growth of vertically aligned $\mathrm{TiO}_{2}$ nanorod arrays using the improved hydrothermal method and their application to dye-sensitized solar cells," J. Alloys Compd., vol. 659, pp. 44-50, 2016.

[20] A. Yuvapragasam, N. Muthukumarasamy, S. Agilan, D. Velauthapillai, T. S. Senthil, and S. Sundaram, "Natural dye-sensitized $\mathrm{TiO}_{2}$ nanorods assembly of broccoli shape-based solar cells," J. Photochem. Photobiol. B Biol., vol. 148, pp. 223-231, 2015.

[21] T. Gupta, J. Cho, and J. Prakash, "Hydrothermal synthesis of $\mathrm{TiO}_{2}$ nanorods: formation chemistry, growth mechanism, and tailoring of surface properties for photocatalytic activities," Mater. Today Chem., vol. 20, p. 100428, 2021.

[22] A. Prathan et al., "Controlled Structure and Growth Mechanism behind Hydrothermal Growth of $\mathrm{TiO}_{2}$ Nanorods," Sci. Rep., vol. 10, pp. 1-11, 2020.

[23] J. Zhang, Q. Xu, Z. Feng, M. Li, and C. Li, "Importance of the relationship between surface phases and photocatalytic activity of $\mathrm{TiO}_{2}$," Angew. Chemie, vol. 120, pp. 1790-1793, 2008.

[24] S.-P. Hong et al., "Comprehensive study on the morphology control of $\mathrm{TiO}_{2}$ nanorods on foreign substrates by the hydrothermal method," Cryst. Growth Des., vol. 18, pp. 6504-6512, 2018.

[25] D. S. Ahmed, M. O. Dawood, and O. N. Salman, "Study and Antibacterial Activity of CdS Thin Films Prepared by Thermal Evaporation Technique (TET)," Materials Science Forum, vol. 1021, pp. 129-137, 2021.

[26] G. Byzynski, C. Ribeiro, and E. Longo, "Blue to Yellow Photoluminescence Emission and Photocatalytic Activity of Nitrogen Doping in $\mathrm{TiO}_{2}$ Powders," International Journal of Photoenergy, vol. 2015, p. 831930, 2015. 
[27] S. Mathew, et al., "UV-Visible Photoluminescence of $\mathrm{TiO}_{2}$ Nanoparticles Prepared by Hydrothermal Method" Journal of Fluorescence, vol. 22, pp. 1563-1569, 2012.

[28] J. Liqiang et al., "Review of photoluminescence performance of nano-sized semiconductor materials and its relationships with photocatalytic activity," Sol. Energy Mater. Sol. Cells, vol. 90, pp. 1773-1787, 2006.

[29] V. Kumar, S. Kr. Sharma, T. P. Sharma, and V. Singh, "Band gap determination in thick films from reflectance measurements," Optical Materials, vol. 12, pp. 115-119, 1999. 